\title{
Фотоэлектрические характеристики фотодиодных ИК ФПУ с учетом пространственного распределения локальной квантовой эффективности
}

\author{
И.И. Ли ${ }^{1)}$, В.Г. Половинкин ${ }^{1,2)}$ \\ ${ }^{1}$ Институт физики полупроводников им. А.В. Ржанова СО РАН, \\ Новосибирск, 630090, пр. Ак. Лаврентьева, 13 \\ ${ }^{2}$ Новосибирский государственный технический университет, Новосибирск, 630073, пр. К. Маркса, 20 \\ тел:+7 (383) 330-7781, факс:+7 (383) 330-5256, эл. почта: irlamlee@isp.nsc.ru
}

DOI 10.34077/RCSP2019-58

Представлены результаты расчетов фотоэлектрических характеристик многоэлементных ИК ФПУ, полученные с учетом пространственного распределения локальной квантовой эффективности для элементов на основе фотодиодов, выполненных на эпитаксиальной пленке материала кадмий-ртутьтеллур. При расчетах, основанных на моделировании методом Монте Карло диффузии фотогенерированных носителей заряда, показано влияние основных фотоэлектрических (длины оптического поглощения, длины диффузии, толщины фоточувствительного слоя) и конструктивных (размеры p-n переходов, шаг элементов) параметров фоточувствительных элементов и оптической системы (диаметр оптического пятна в фокальной плоскости ИК ФПУ от точечного источника) на фотоэлектрические характеристики ИК ФПУ [1-3]. При расчетах принято, что распределения интенсивности излучения в пятне определяется дифракцией Фраунгофера на круглом отверстии (формула Эйри [4]). Представлены методики расчетов фотоэлектрических характеристик многоэлементных ИК ФПУ: пространственного разрешения, пороговой чувствительности (NEP), коэффициентов фотоэлектрической связи.

На Рисунке приведен пример результатов расчета пороговой чувствительности в относительных единицах при однородном освещении и для точечных источников излучения, при условии, что энергия в пятне не зависит от диаметра пятна. Показано, что NEP ИК ФПУ для малоразмерных объектов определяется, в основном, пространственным распределением локальной квантовой эффективности фоточувствительных элементов (ФЧЭ).

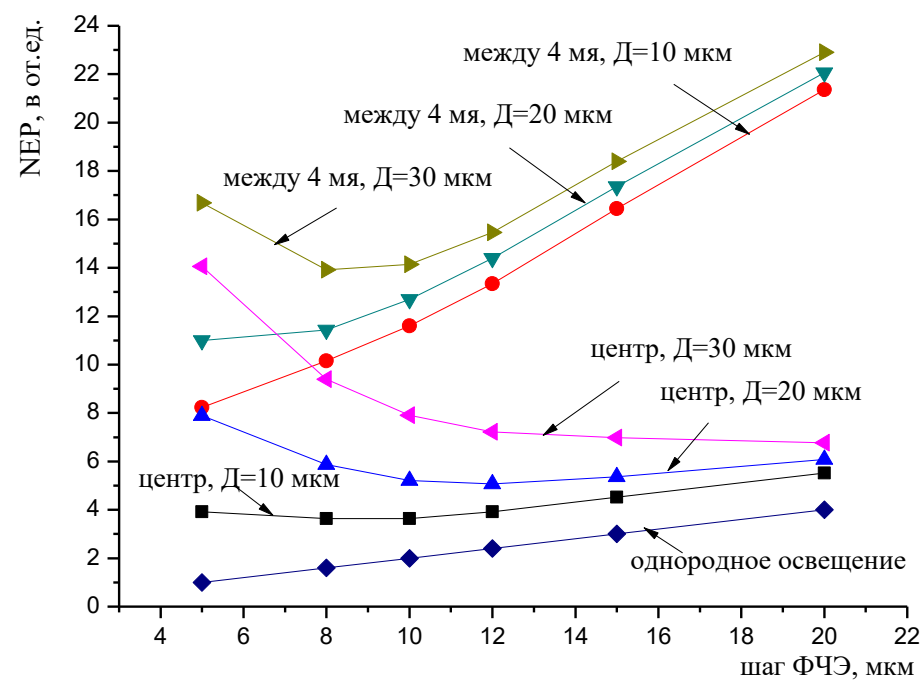

Зависимости NEP от размера ФЧЭ, работающего в режиме ограничения фоном, для крупноформатных и точечных источников с диаметрами оптического пятна 10, 20, 30 мкм, при двух положениях центра оптического пятна относительно ФЧЭ (центр пятна проецируется в центр ФЧЭ, центр пятна между четырьмя соседними ФЧЭ).

Приведенные в работе зависимости дают возможность прогнозировать основные фотоэлектрические характеристики многоэлементных ИК ФПУ для крупноформатных и малоразмерных объектов при произвольных уровнях фонового излучения, спектрального диапазона, времени накопления, квантовой эффективности ФЧЭ.

\section{Лumepamypa}

[1] V.G. Polovinkin, V.A. Stuchinsky, A.V. Vishnyakov, I.I. Lee. //IEEE Transaction on Electron Device.2018. Vol.65. No.11. P.4924- 4930.

[2] В.Г. Половинкин, В.А. Стучинский, А.В. Вишняков, И.И. Ли. //Автометрия. 2018. Т.54. №6. стр. $114-121$.

[3] В.Г. Половинкин, В.А. Стучинский, А.В. Вишняков, И.И. Ли. //Успехи прикладной физика.2018. Т.6. №5. стр.422-428.

[4] М. Борн, Э. Вольф. Основы оптики. М. «Наука». 1973. 720 стр. 